\title{
Microbial Diversity Associated with Organic Fertilizer Obtained by Composting of Agricultural Waste
}

\author{
Natalia Escobar*, Victor Solarte \\ Cundinamarca University, Área Verde Research Group, Colombia. \\ * Corresponding author. email: nataliaescobar.e@gmail.com. \\ Manuscript submitted January 30, 2015; accepted March 24, 2015. \\ doi: 10.17706/ijbbb.2015.5.2.70-79
}

\begin{abstract}
A common denominator that affects the production areas is the dramatic loss of fertility and thus, the natural productive capacity of soils through a sustained process of erosion. The problem of soil loss was largely due to improper production practices, such as monoculture, chemical fertilizers, pesticides, intensive farming, genetically modified seeds, among others. Agroecological alternative allows recovery of soils, compost making, and its quality depends of largely microbial diversity associated with it. The aim of the work focused on microbial characterization of different mixtures of agricultural waste in order to determine quality parameters. Through a randomized block design, six different mixes were evaluated in the village of Fusagasugá (Colombia). The OM, OC, macro and micronutrients chemical indicators were obtained from the soil laboratory at the University of Tolima, for microbial characterization macroscopic and microscopy techniques were used in the Laboratory of Microbiology of the University of Cundinamarca. Principal Component Analysis (PCA), Canonical Correspondence Analysis (CCA) incorporating with the Partial Least Squares (PLS) was made. XLSTAT statistical package (2009.3.02) was used. The most important microorganisms were, Streptomyces, Arthrobacter, Aspergillus and Penicillium genera. Treatments that presented the best quality in relation to chemical and microbiological variables were mixtures containing double burden of animal, especially hens and pig manure.
\end{abstract}

Key words: Agroecology, soil, bacteria, fungi.

\section{Introduction}

Agroecology is emerging today as the fundamental science to guide the conversion of conventional production systems to more diversified and self-sufficient systems [1]. This agroecology uses ecological principles that favor natural processes and biological interactions to optimize synergies so that agrobiodiversity is able to subsidize itself key processes such as the accumulation of organic matter, soil fertility, biotic mechanisms regulating pest and crop productivity [2].

Unfortunately, much of the soils used in agricultural activities in Colombia are losing their fertility and health properties, this crisis is largely due to the practices of conventional agriculture have been used for many years, some of these practices are: application of chemical fertilizers, monoculture, intensive tillage, land degradation through soil erosion, compaction, decline in organic matter and biodiversity associated with it, salinization, depletion of groundwater, deforestation and desertification; and pest outbreaks due to widespread monoculture, genetic uniformity, elimination of natural enemies and pesticide resistance developed by insects, weeds and crop diseases [3], [4].

One way to start or where efforts should focus substitution is chemically derived inputs to agriculture 
agroecology considering that these transitional periods can be long, and to be given the time needed to restore soil life, his structure and organic matter as well as recover the beneficial fauna [2], [4], [6]. An agroecological alternative, is to develop composting from the same organic waste generated in production systems [3].

Microbial populations are the active components of biodegradation processes and conversion during composting. Thus, compost quality is directly related to the composition and sequence of microbial communities in the process, being the fungi and bacteria that perform the degradation of organic matter [6]. Thus, this study aims to characterize different microbial mixtures of agricultural waste in order to determine quality parameters.

\section{Methodology}

\subsection{Study Area}

The experimental units were established in the Esperanza Farm located in the town of Fusagasugá,

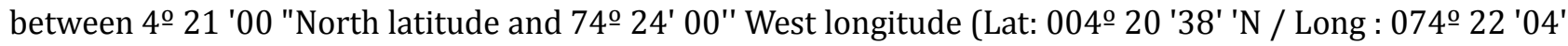
'W), at an average altitude of 1,720 m (Fig. 1).

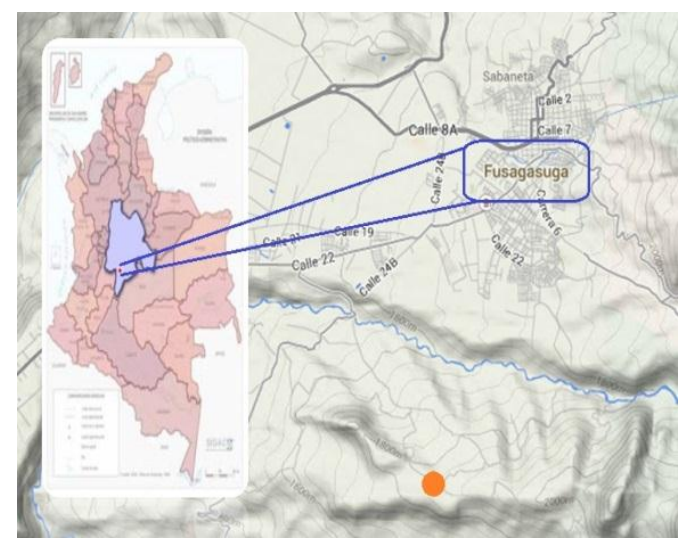

Fig. 1. Location of Fusagasugá urban area inside the blue box and the orange La Esperanza farm. Source: www.google.com/maps.

\subsection{Phase Field}

The substrates on farm were prepared in sheeting microcomposting $0.80 \mathrm{~m} \times 1.20 \mathrm{~m}$, which were filled with approximately $45 \mathrm{~kg}$ of each of the mixtures already determined (Table 1).

According to the optimum $\mathrm{C} / \mathrm{N}$ ratio (25-30), for starting the composting process, it was necessary to prepare mixtures. To improve this ratio, further litter was used, obtaining results close to those required. Plant residues with high content of lignin and other polyphenols, are more resistant to decompose poor materials rich in these compounds and nitrogen compounds decompose quickly.

In this regard [6], litter of tree species with high $\mathrm{C} / \mathrm{N}$ and polyphenol-rich decomposed relatively slowly, compared with the leaves of plants rich in nitrogen and soluble carbohydrates but low in polyphenols. The litter was obtained from coffee plants and was used primarily to increase the $\mathrm{C} / \mathrm{N}$ in the mixtures, as these contain high levels of carbon (40\%-50\%) and other nutrients. The parameter $\mathrm{C} / \mathrm{N}$ ratio is associated with microbial dynamics in the substrates used, by varying mixtures in chemical composition of microbial populations which are stimulated and therefore optimize the composting process.

\subsection{Laboratory Phase}




\subsubsection{Evaluation of chemical variables}

Chemical fertilizers variables were: carbon/nitrogen $(\mathrm{C} / \mathrm{N})$, cation exchange capacity (CEC), organic matter (OM), organic carbon (OC), micronutrients ( $\mathrm{Ca}, \mathrm{Mg}, \mathrm{Na}, \mathrm{Fe}, \mathrm{Mn}, \mathrm{Cu}, \mathrm{Zn}, \mathrm{S}, \mathrm{B}, \mathrm{Si}$ ) and macronutrients $(\mathrm{N}, \mathrm{P}, \mathrm{K})$. The samples were sent to the soil laboratory at the University of Tolima.

Table 1. Organic Materials Used for Each Treatment

\begin{tabular}{ll}
\hline \hline Mixture & Components \\
\hline Mixture 1 & Cattle manure, tomatoes, eggshells, vegetables wastes \\
Mixture 2 & Hens manure, coffee pulp, tomatoes wastes \\
Mixture 3 & Pigs manure, grass, citrus wastes \\
Mixture 4 & Hens and pigs manure, coffee pulp, eggshells, vegetables wastes \\
Mixture 5 & Cattle and hens manure, citrus wastes \\
Mixture 6 & Cattle and pigs manure, grass and tomatoes wastes
\end{tabular}

\subsubsection{Microbiological characterization}

For identification of microorganisms in 90 days, the composting process, macroscopic and microscopic techniques were applied in the Laboratory of Microbiology of the Universidad de Cundinamarca, taking into account Colombian Technical Standard (NTC 4491-2) on microbiological procedures.

\subsubsection{Bacteria: Macroscopy}

Macroscopic characterization was based on the following criteria: colony size (punctate, small, medium, large); color; form (regular, round, oval, irregular filamentous rhizoids); elevated (flat, high, pitching convex) colonies; edges (length, wavy, serrated, filamentous curly); surface; odor (ammonia, fetid, sweet) and growth (heavy, moderate, low).

Microscopy: Gram staining [7] is performed, and the miniaturized identification method used by the BBL Crystal kit (BD Diagnostic Systems Europe mark) is based on the use of specific substrates and degradation by microorganisms detected by different systems indicators [8], for bacilli Gram (-) belonging to the family Enterobacteriaceae, and the most frequent isolates of Gram bacilli (-), non-fermenting glucose. Furthermore, a kit for Gram (+) (cocci and rods) was used.

Fungi: to identify possible gender and species of fungi in the treatments, it was necessary for the use of taxonomic keys, for this, it was taken into account, the macro and microscopic characteristics, as it was necessary to examine the isolates from each of the strains and contrast with the literature.

Macroscopy: in this step, the same patterns of reading and description of bacterial colonies were used.

Microscopy: the art of tape was used for microscopic observation. This technique is one of the most widely used, because it keeps the original juxtaposition of the spores and hyphal segments [7]. Its realization became a bend of a strip of $4 \mathrm{~cm}$, with the adhesive side out and being held with tweezers. The adhesive side was firmly pressed against the surface of the fungal colony to study. The aerial mycelium, joins the adhesive surface, therefore, it was easily separated from the colony. The strip of tape sample was placed on a drop of blue Lactophenol with a slide and continued with observations.

\subsubsection{Microculture method}

To achieve more accurate observation of fungal structures in situ ([9], a petri dish was taken with an easel glass in $\mathrm{u}$, to avoid drying; $5 \mathrm{ml}$ of sterile water was deposited in the box; a slide was placed on the stand 
with a sterile pipette, a layer of agar is placed on the surface of the sheet, finally, seeded in the center, slightly cultured and was incubated at $25^{\circ} \mathrm{C}$ for 48 to 72 hours [8].

\subsection{Data Analysis}

The physico-chemical variables were considered together by a Principal Component Analysis (PCA), which was built on a correlation matrix $\mathrm{R}$ through technique (associating and standardizes the variables). To analyze the correlation between the bacterial and fungal communities and physicochemical variables measured in the six treatments. Canonical Correspondence Analysis (CCA) was used incorporating with the Partial Least Squares (PLS).

The ACC-PLS seek a linear relationship between a set of predictor variables (in this case with only the physicochemical variables) and a set of measured or observed criteria (bacterial and fungal communities); tries to find indicators of the first group to explain the indicators of the second group. The Principal Component Analysis is made on a correlation matrix $\mathrm{R}$ through the technique (associating and standardizes the variables) in order to reduce the large number of environmental variables and relate them to the relative abundances of different hydrobiological communities. XLSTAT statistical package (2009.3.02) was used to develop the numerical analysis.

\section{Results and Discussion}

\subsection{Chemical Variables}

The Principal Component Analysis for physico-chemical parameters (Fig. 1), indicated that all chemical variables were positively correlated, except $\mathrm{pH}$ and Fe. The treatments 4, 5 and 6 are strongly influenced by some variables ( $\mathrm{P}, \mathrm{K}, \mathrm{OM}, \mathrm{OC}, \mathrm{Zn}, \mathrm{Mg}$ and $\mathrm{N}$ ). These results might be related to differences in the composition of the mixtures, since these treatments were more and contained different content of manure. The most important chemical characteristic of the substrates was their elemental composition. Agronomic utility of waste to be composted was possible depending on the availability of nutrients they have. Ref. [10] indicated that microorganisms could only take simple compounds, so that more complex molecules were broken into simpler to be assimilated.

Ref. [11] reported the highest values of OM (44.7\%) in animal materials compared with materials of household origin (kitchen waste). In the composts where only as many plant remains are included, a reduction occurred in the NPK nutrient content. Production systems using more inputs, would waste with higher concentrations of nutrients and therefore produce more enriched compost [12].

The results can't demonstrate a positive effect on soil fertility, but it could predict that the higher OM content in the mixtures, the higher nutrient content would be found, which is related to the types of material used and the preparation of the mixtures [13], indicating that in the case of composting, these exert a fertilizer in the soil and also contribute to improved physical and chemical soil.

It should be noted that carbon is used by microorganisms as a source of energy, while nitrogen is used for the synthesis of a substance and for the vital functions of the microorganisms [12], That is when the $\mathrm{C} / \mathrm{N}$ is greater than 40 , the microorganisms take much time to break down waste for lack of nitrogen decreasing composting performance, if the $\mathrm{C} / \mathrm{N}$ is low, losses of nitrogen in ammoniacal form occur due to significant temperature elevations.

A mature compost quality has the following characteristics: dark color, no odor, having environment temperature, the average particle size $10 \mathrm{~mm}$ and the ratio $\mathrm{C} / \mathrm{N}$ ranging from 10 to 15 . Ref. [9] and Ref. [16] indicate that the $\mathrm{C} / \mathrm{N}$ ratio for a perfect fully matured compost is close to 10 , similar to humus. The treatments evaluated according to the values and parameters mentioned, generated a mature compost.

\subsection{Microbiological Characterization}


Bacteria identified (Table 2) corresponded to microorganisms commonly found in the composting process [10]. The most abundant ones are Arthrocacter and Streptomyces genera, the former is very common in the soil, bacteria are metabolically versatile, producing different enzymes that allow them to grow in a wide range of substrates [11]. Streptomyces is the largest genus of actinobacteria, predominantly found in soil and decaying vegetation and most produce spores [12]. These microorganisms are capable of using complex organic compounds as carbon and energy source obtained by breaking these products in the soil [10], this skill degradation makes these bacteria are essential to the production of soil fertility for agriculture [13].

Table 2. Abundance and Diversity of Bacteria Found in Treatments

\begin{tabular}{|c|c|c|c|c|c|c|c|c|c|c|c|c|c|}
\hline \multicolumn{14}{|c|}{ Bacteria } \\
\hline Treatments & A & B & En & Es & $\mathrm{Mi}$ & Mo & $\mathrm{Nb}$ & Ns & $\mathrm{Pa}$ & $\operatorname{Pr}$ & Ps & Sc & $\mathrm{Sm}$ \\
\hline 1 & +++ & + & - & ++ & ++ & - & +++ & + & - & ++ & +++ & - & + \\
\hline 2 & + & +++ & ++ & ++ & - & ++ & - & + & - & ++ & + & - & +++ \\
\hline 3 & +++ & ++ & + & + & +++ & - & - & + & - & - & + & - & +++ \\
\hline 4 & +++ & +++ & ++ & ++ & + & + & +++ & +++ & + & ++ & +++ & + & +++ \\
\hline 5 & +++ & ++ & ++ & - & + & + & + & + & - & + & +++ & + & +++ \\
\hline 6 & +++ & +++ & + & + & - & + & +++ & + & + & + & +++ & + & +++ \\
\hline
\end{tabular}

(Absent -), (Mild +), (Moderate ++), (Heavy +++)

$\mathrm{A}=$ Arthrobacter; $\mathrm{B}=$ Bacillus; $\quad \mathrm{En}=$ Enterobacter; $\quad$ Es=Escherichia; $\mathrm{Mi}=$ Micrococcus; $\mathrm{Mo}=$ Morganella; $\mathrm{Nb}=$ Nitrobacter; Ns=Nitrosomonas; $\mathrm{Pa}=$ Paucimonas; $\mathrm{Pr}=$ Proteus; $\mathrm{Ps}=$ Pseudomonas; $\mathrm{Sc}=$ Staphylococcus; $\mathrm{Sm}=$ Streptomyces

According to the Canonical Correspondence Analysis (CCA) incorporating the Partial Least Squares (-Pls), the $\mathrm{Nb}$ bacteria, Ps, B, Ns, En and Pa were associated with treatments 4 and 6, the least bacterial diversity was 3 (Fig. 2). This can be related to the components of the mixtures, in the case of treatments 4 and 6 composition mostly contained pig and cattle manure. As shown by Ref. [14], the cattle manure contains other substances such as urine, peeling and endogenous fibrous forage wastes, among others, bacterial loads containing high inherent in this type of organic waste. As reported in Ref. [15], the cattle manure is rich in carbon, which is a basic nutrient source for bacteria and fungi.

The hens and pig manure contain nutrients such as nitrogen, phosphorus, potassium, calcium, magnesium, iron, manganese, zinc, copper and boron and, depending on its origin, other organic materials can provide a greater or lesser amount. Ref. [16] reports that these nutrients allow growth of different bacterial populations and in composting processes these microbial loads are high (greater than 1.0E8 CFU / $\mathrm{ml})$.

Ref. [17] expressed during the composting process, a selection of microorganisms basically was governed by the availability of nutrients and temperature, evolving from the initial predominance of microorganisms, such as bacteria which can metabolize easily degradable organic compounds, to produce less biodegradable degrading complex organic compounds such as fungi and actinomycetes, and it is the characteristic of the maturation phase. In each of the intermediate stages, temperature determined the specific population according to their tolerance to these conditions.

Fungi identified (Table 3) have been previously described as part of systems for biotransformation of organic material [18]. 21 genera were recorded, the most abundant ones were Aspergillus and Penicillium, these fungi were isolated in nearly all simple treatments. In this regard, Ref. [19] stated that most commonly found species of cellulolytic fungi in the compost materials are Aspergillus, Penicillium, Fusarium and Trichoderma. 
Although cellulose and hemicellulose are degraded more slowly than sugar or starch, lignin is the toughest and usually organic residue, the latest product that degrades the food chain. The Basidiomyces play an important role in lignin degradation. In a study [20] on the microbial analysis composting plants, using cow dung as inoculum, it isreported that the population of fungi Aspergillus, was the most predominant.

According to the Canonical Correspondence Analysis (CCA) with Partial Least Squares (PLS), in bacteria mixtures containing greater microbial load of manure present high diversity (Fig. 3), fungi: $\mathrm{Al}, \mathrm{Ma}, \mathrm{Pe}, \mathrm{Th}, \mathrm{Cl}$, $\mathrm{Ph}, \mathrm{Td}, \mathrm{V}$, were associated with treatments 5 and 6 and less fungal diversity are presented in treatments 1 and 3 (Fig. 4).

A study [19], which was about manure as a nutritional alternative used in mixtures, mentioned that the main species of Mucorales fungi were detected, Discomycetes and Basidiomycetes. Because manure is a product rich in carbon which is a basic nutrient source for fungi found. Ref. [20] found similar results, indicating that after the carbon is readily biodegradable in biochemical structures, Mucorales die, leaving more easily degraded by fungi of the Ascomycetes and Basidiomycetes respectively.

It was also observed that most gender diversity occurred in fungi, this result may be associated with the statement of Ref. [21] that the cooling stages and final maturation were characterized by the growth of a new different mesophilic community to the initial mesophilic phase. In this period fungi and actinomycetes capable of degrading complex compounds predominated. These organisms recolonize the material from the surrounding environment, or the germination of spores that survived the thermophilic stage and remained there until the end.

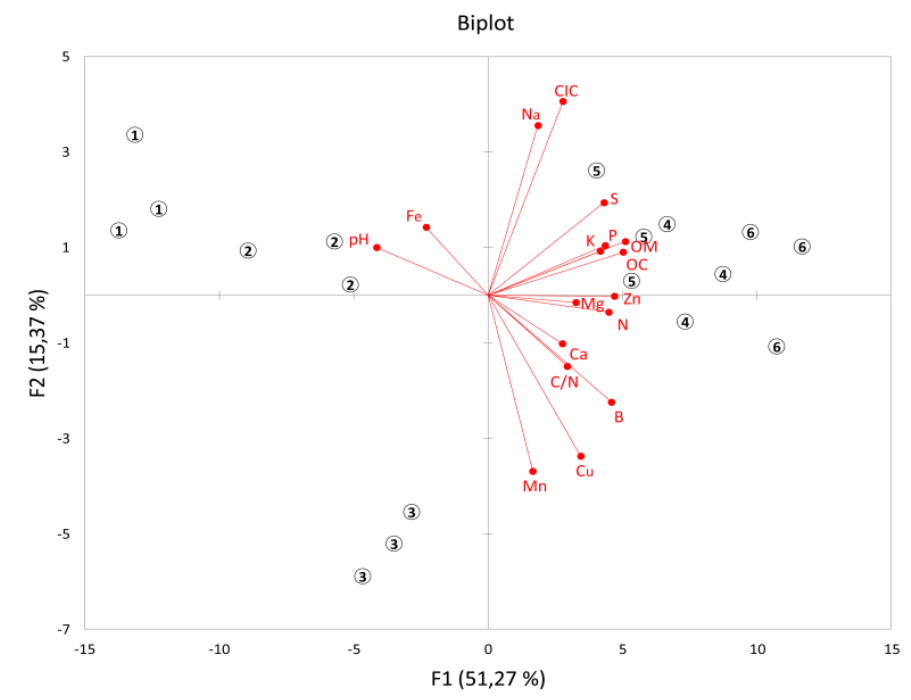

Fig. 2. Principal component analysis for physico-chemical parameters.

Table 3. Abundance and Diversity of Fungi Found in Treatments

\begin{tabular}{|c|c|c|c|c|c|c|c|c|c|c|c|c|c|c|c|c|c|c|c|c|c|}
\hline \multicolumn{22}{|c|}{ Fungi } \\
\hline Treatments & $A l$ & As & $\mathrm{Ce}$ & $C l$ & $H$ & $M a$ & Mo & $N$ & $\mathrm{Pe}$ & $P h$ & $\operatorname{Pr}$ & $R$ & So & $S t$ & $S i$ & $T v$ & $T h$ & $T d$ & $T c$ & $V$ & $Z$ \\
\hline 1 & ++ & ++ & - & - & + & - & - & - & +++ & - & ++ & - & - & - & - & + & - & - & - & ++ & + \\
\hline 2 & + & +++ & - & + & - & ++ & - & - & ++ & + & - & - & ++ & - & - & - & + & ++ & - & + & + \\
\hline 3 & - & - & + & - & - & - & - & - & +++ & - & - & - & - & ++ & + & - & - & - & ++ & - & - \\
\hline 4 & ++ & +++ & ++ & + & ++ & ++ & + & - & +++ & + & + & ++ & + & + & + & + & ++ & +++ & - & + & ++ \\
\hline 5 & - & +++ & - & - & + & - & ++ & + & ++ & - & - & + & - & - & ++ & + & - & + & - & ++ & - \\
\hline 6 & ++ & +++ & - & ++ & + & - & + & - & +++ & - & + & + & ++ & + & - & - & + & ++ & + & - & ++ \\
\hline
\end{tabular}

(Absent -), (Mild +), (Moderate ++ ), (Heavy +++ ) 
$\mathrm{Al}=$ Alternaria $; \mathrm{As}=$ Aspergillus; $\mathrm{Ce}=$ Cephaliophora $; \mathrm{Cl}=$ Cladosporium; $\mathrm{H}=$ Humicola $; \mathrm{Ma}=$ Macrosporium; $\mathrm{Mo=Moniliella;}$ $\mathrm{N}=$ Nigrospora; $\mathrm{Pe}=$ Penicillum; $\mathrm{Ph}=$ Phoma; $\mathrm{Pr}=$ Preussia; $\mathrm{R}=$ Rhizopus; So=Sordaria; $\mathrm{St}=$ Staphylotrichum; Si=Sistotrema; $\mathrm{Tv}=$ Thielavia; Th=Thysanophora; $\mathrm{Td}=$ Trichoderma; Tc=Trichurus; $\mathrm{V}=$ Verticillium; $\mathrm{Z}=$ =Zyorhynchus

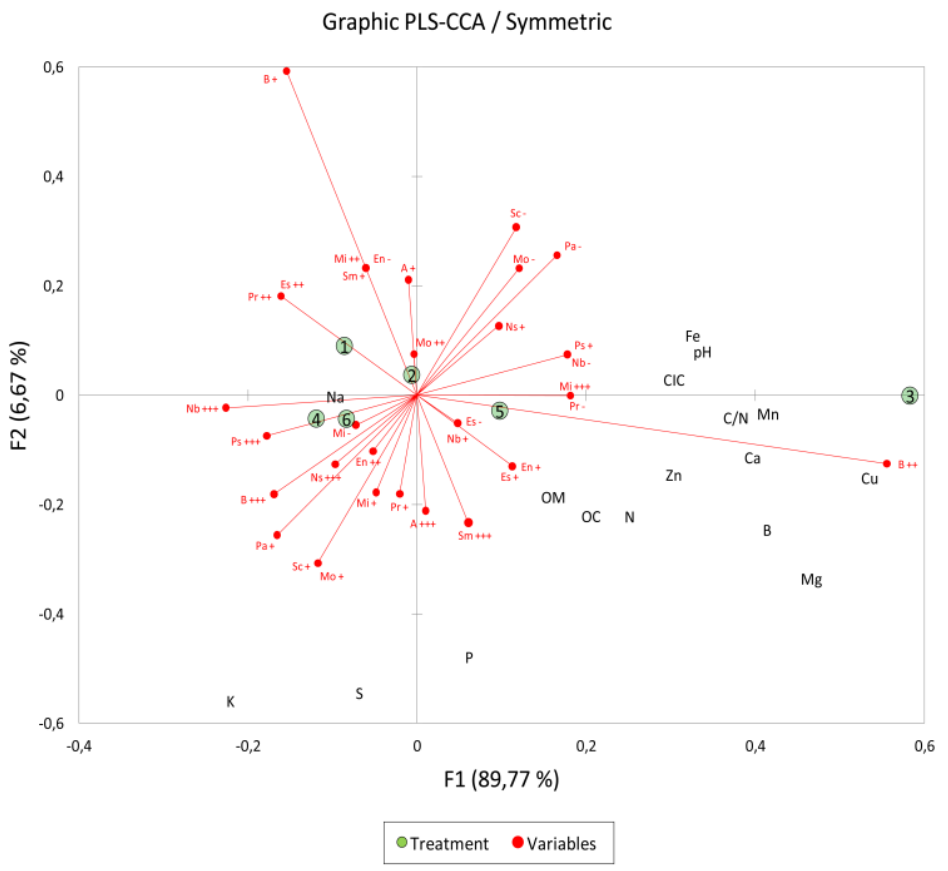

Fig. 3. PLS-CCA Bioplot of bacteria community.

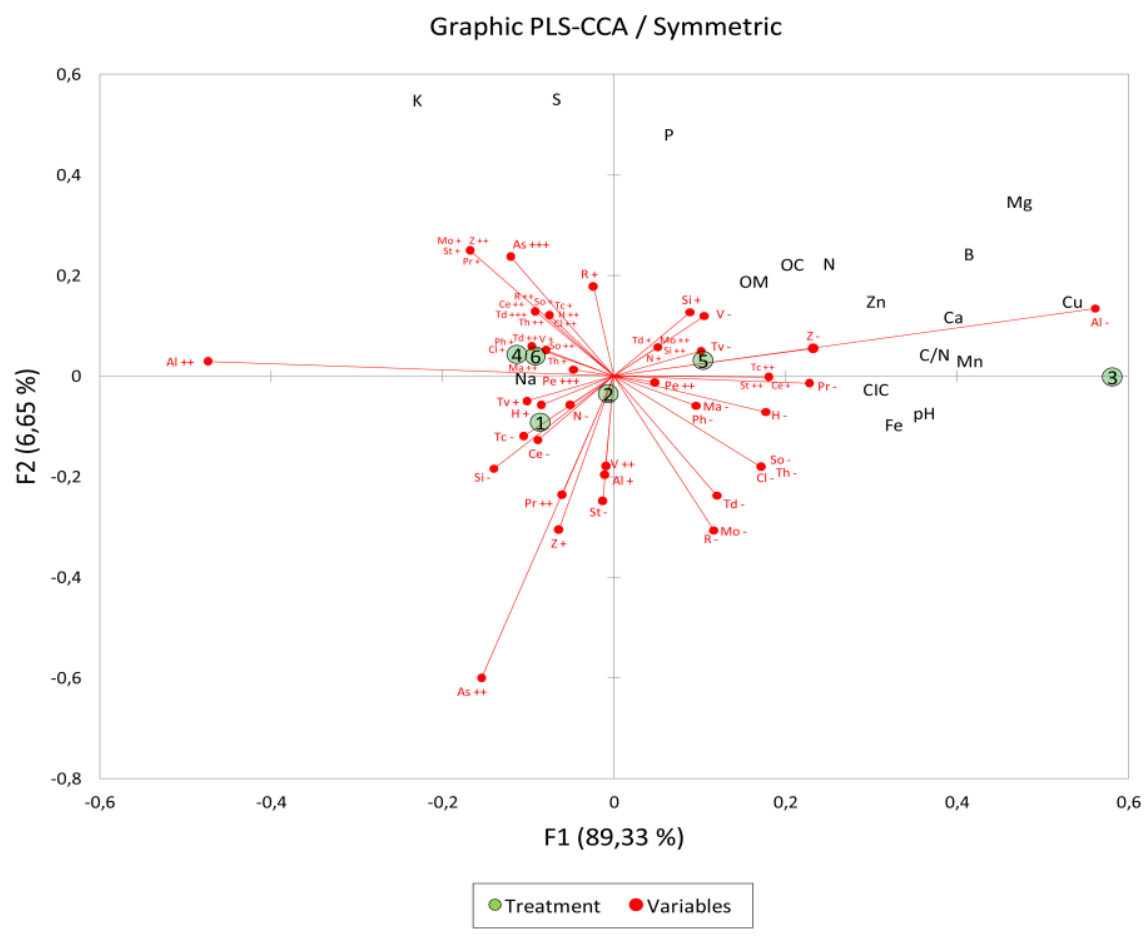

Fig. 4. PLS-CCA Bioplot of bacteria community.

According to Ref. [18], it was indicated that variations between micro and macro elements content within a treatment may be due to microbial activity and dynamics with abiotic factors, allowing heterogeneity of biological populations and availability of minerals. Ref. [22] mentioned that microorganisms break down 
organic substances into their basic components, eg. water, carbon dioxide and minerals. In this sense, the activity of soil microbiota depends on factors that determine the conditions of this medium, such as the structure and porosity, oxygen presence, temperature ranges, moisture and nutrient availability among others.

Ref. [23] explained that, soil microorganisms lead the biodegradation of organic matter and are an important reservoir of labile C, N and P. Swift (1997), also indicated that some microorganisms are able to establish mutual symbiosis with plants, such as growth-promoting rhizobacteria of the genus Azospirillum to fix atmospheric nitrogen in the endo of grasses, and others as arbuscular mycorrhizae that colonize plant roots.

The actual population of bacteria and fungi depends on the type of source material, the local and amendments used condition. Microbial community starting substrates, together with those that colonize the compost pile from the surrounding environment, constitutes the set of biological agents responsible for biotransformation process. As mentioned [24], the type of predominant microorganism in each phase depends on its competitive efficiency and its ability to survive, against the prevailing conditions.

The interaction between various functional microorganisms groups depends on the available nutrients and changes in the biochemical mechanisms, during the transformation of matter organic and inorganic. The population of fungi was more abundant, and diversity than bacteria, in part because these microorganisms, filamentous forms taken, giving rise to a pseudomycelium, like fungi, develop more slowly and have greater capacity to metabolize organic compounds.

In general, mixtures with more than one type of animal manure had higher diversity and abundance of microbial populations, which highlights the importance of mixes from simple to get better results in the use of organic waste.

Organic matter is the heart of soil and agroecological practices should be provided to keep balance. The first objective of a good crop management of soil should be to create the conditions for a highly diverse community of soil organisms. The soil biodiversity is an important part of the health and stability of the agroecosystem. Microbial populations are influenced by crop management and waste. Soil management and crop may affect the population dynamics of soil organisms.

The composting process time in this study, 75 days were less than that reported in the literature ( 90 days) in this study were stabilized on treatment day 75 , after which no changes in the dynamics generated bacteriological and physical-chemistry.

It is suggested that in the search for designing alternatives that take advantage of the waste produced, to mitigate environmental pollution and recover productive soil conditions, by improving its structure, fertility and biological activity, composting has proven to be an alternative feasible and easy to use in both temperate and tropical regions. Today there is a recent interest in developing basic and applied research to gain insight into the biological, biochemical, physical and environmental processes of compost production.

\section{Acknowledgment}

The authors express acknowledgement to the Research Center of the University of Cundinamarca, for the facilities and financial support provided for Basic studies that gave rise to this article.

\section{References}

[1] Altieri, M. A. (2010). Agroecology, small farms and food sovereignity. Monthly Review, 61(3), 102-111.

[2] Dawson, C. J., \& Hilton, J. (2011). Fertiliser availability in a resource-limited world: Production and recycling of nitrogen and phosphorus. Food Policy, 36, 14-22.

[3] Altieri, M. A. (2010). Agroecology: The science of natural resource management for poor farmers in 
marginal environments. Agriculture, Ecosystems and Environment, 93, 1-24.

[4] Dalgaard, T., Hutchings, N. J., \& Porter, J. R. (2004). Agroecology, scaling and interdisciplinarity. Agriculture Ecosystems and Environement, 100, 39-51.

[5] Wezel, A., Bellon, S., Doré, T., Francis, C., Vallod, D., \& David, C. (2009). Agroecology as a science, a movement and a practice. A review. Agronomy for Sustainable Development, 29, 503-515.

[6] Palm, C. A., Gachengo, C. N., Delve, R. J., Cadisch, G., \& Giller, K. E. (2004). Organic inputs for soil fertility management in tropical agroecosystems: Application of an organic resource database. Agriculture Ecosystems and Environement, 83, 27-42.

[7] Madigan, M., Martinko, J. M., \& Parker, J. (2000). Brock Biology of Microorganisms (9th ed.). Upper Saddle River: Prentice Hall.

[8] Paillat, J. M., \& Guerrin, F. (2011). Combining individual and collective management of animal manure to reduce environmental impacts on a territory scale. Proceeding of 19th International Congress on Modelling and Simulation (pp. 843-849). Australia: Perth.

[9] Ayuk, E. T. (2005). Social, economic and policy dimensions of soil organic matter management in sub-Sahara Africa: Challenges and opportunities. Nutrient Cycling in Agroecosystems, 61, 183-195.

[10] Tittonell, P., Vanlauwe, B., Ridder, N., \& Giller, K. E. (2007). Heterogeneity of crop productivity and resource use efficiency within smallholder Kenyan farms: Soil fertility gradients or management intensity gradients? Agric. Syst., 94, 376-390.

[11] Ricardo, M., \& Russell, Y. (2006). A survey of soil fertility status of four agroecological zones of Mozambique. Soil Science, 11, 902-914.

[12] Legros, S., Doelsch, E., Feder, F., Moussard, G., Sansoulet, J., \& Gaudet, J. (2012). Fate and behaviour of Cuand $\mathrm{Zn}$ from pig slurry spreading in a tropical water-soil-plant system. Agriculture, Ecosystems and Environment, 164, 70-79.

[13] Diacono, M., \& Montemurro, F. (2010). Long-term effects of organic amendments on soil fertility. A review. Agronomy for Sustainable Development, 30, 401-422.

[14] Bernal, M. P., Alburquerque, J. A., \& Moral, R. (2009). Composting of animal manures and chemical criteria for compost maturity assessment. A review. Bioresource technology, 100(22), 5444-5453.

[15] Asefa, D. T., Oba, G., Weladji, R. B., \& Colman, J. E. (2004). An assessment of restoration of biodiversity in degraded high mountain grazing lands in northern Ethiopia. Land Degradation and Development, 14 , 25-38.

[16] Laniak, G. F., Olchin, G., Goodall, J., Voinov, A., Hill, M., \& Glynn, P. (2009). Indicator of potential residual carbon in soils after exogenous organic matter application. European Journal of Soil Science, 60, 297-310.

[17] Paredes, C., Roig, A., Bemal, M. P., Sánchez-Monedero, M. A., \& Cegarra, J. (2000). Evolution of organic matter and nitrogen during co-composting of olive mill wastewater with solid organic wastes. Biology and Fertility of Soils, 32(3), 222-227.

[18] Adeniran, J. A., Taiwo, L. B., \& Sobulo, R. A. (2003). Effects of organic wastes and method of composting on compost maturity, nutrient composition of compost and yields of two vegetable crops. $J$. of Sustainable Agriculture, 22, 95-101.

[19] Pérez, A., Hermann, V., Alabouvette, C., \& Steinberg, C. (2006). Response of soil microbial communities to compost amendments. Soil Biol. Biochem., 38(3), 460-470.

[20] Ryckeboer, J., Megaert, J., Coosemans, J., Deprins, K., \& Swings, J. (2003). Microbiological aspects of biowaste during composting in a monitored compost bin. J. Appl. Microbiol., 94(1), 127-137.

[21] Saison, C., Degrange, V., Oliver, R., Millard, P., Commeaux, C., Montange, D., et al. (2006). Alteration and resilence of the soil microbial community following compost amendment: Effects of compost level and 
compost-borne microbial. Environmental Microbiology, 8 (2), 247-257.

[22] Castillo, A. E., Quarín, S. H., \& Iglesias, M. C. (2000). Vermicompost chemical and physical characterization from raw and mixed organic wastes. Agricultura Técnica, 60 (1), 74-79.

[23] Descheemaeker, K., Muys, B., Nyssen, J., Poesen, J., Raes, D., \& Haile, M. (2006). Litter production and organic matter accumulation in exclosures of the Tigray, Ethiopia. Forest Ecology and Management, 233(1), 21-35.

[24] Adegunloye, D. V., Adetuyi, F. C., Akinyosoye, F. A., \& Doyeni, M. O. (2007). Microbial analysis of compost using cowdung as booster, Pakistan. Journal of Nutrition, 6(5), 506-510.

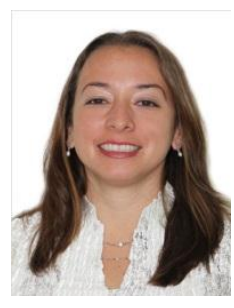

Natalia Escobar was born on July 21, 1978 in a smalltown fusagasugá southern of Bogota, Colombia. She attended at Nueva Granada Militar University in Bogota, where she studied biology, graduating with a bachelor of science degree in 2011. Actually she is a Ph.D. candidate in agroecology at the Antioquia University.

For more than eight years, she has been working as a teacher and researcher at the Faculty of Agricultural Sciences at the University of Cundinamarca. Her research has focused primarily on agroecology, soil microbiology, sustainable management of agricultural systems and rural development. She is a consultant for other research groups and the Agriculture Ministry.

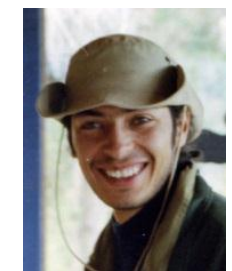

Victor Solarte was born on June 20, 1973 in Pasto, Colombia. He is a biologist at the Universidad de Nariño, Colombia. He received the MSc from Universidad Nacional de Colombia, with specific training in ecology, numerical analysis, environmental studies, paleoecology and palynology. Throughout his practice, he has developed research projects in the areas of environmental studies, ecology, paleoecology and conservation of wildlife as a university teacher. 